\title{
Hydrocephalus associated to congenital Zika syndrome and shunting
}

\author{
Beuy Joob $^{1}$ - Viroj Wiwanitkit ${ }^{2}$
}

Received: 1 November 2017 / Accepted: 9 November 2017 /Published online: 15 November 2017

(C) Springer-Verlag GmbH Germany, part of Springer Nature 2017

Dear Editor:

We read the publication on "Hydrocephalus associated to congenital Zika syndrome and shunting" with a great interest [1]. Jucá et al. concluded that "This series points out the possibility of hypertensive hydrocephalus development in CZS patients. Affected children may benefit from VP shunt insertion. These findings suggest a dual pathology association: fetal brain disruption and primary cortical malformation by the virus itself and hypertensive hydrocephalus [1]." The observation of hydrocephalus in infected infant is totally different from the finding in our country where the infected infant is usually asymptomatic [2] and the neuroimaging usually shows negative finding $[3,4]$.

Nevertheless, in case that there is hydrocephalus, there is still no specific guideline for management. Placing of shunt might be a good alternative but placing of shunt in Zika virus-infected case should be seriously considered on its risk and benefit. The important possible complication is the shunt failure due to the induction of subclinical meningoventriculitis [5].
Compliance with ethical standards

Conflict of interest None.

\section{References}

1. Jucá E, Pessoa A, Ribeiro E, Menezes R, Kerbage S, Lopes T, Cavalcanti LP (2017) Hydrocephalus associated to congenital Zika syndrome: does shunting improve clinical features? Childs Nerv Syst. https://doi.org/10.1007/s00381-017-3636-2

2. Wiwanitkit S, Wiwanitkit V (2016) Afebrile, asymptomatic and nonthrombocytopenic Zika virus infection: don't miss it. Asian Pac J Trop Med 9(5):513. https://doi.org/10.1016/j.apjtm.2016.03.036

3. Joob B, Wiwanitkit V (2017) Fetal magnetic resonance imaging of fetus with Zika virus infection. Pediatr Neurol 68:e1. https://doi.org/ 10.1016/j.pediatrneurol.2016.11.009

4. Wiwanitkit V (2016) Neonatal neuroradiological aspects in Zika virus infection. Childs Nerv Syst 32(8):1349. https://doi.org/10.1007/ s00381-016-3102-6

5. Visagan R, Livermore LJ, Kelly D, Magdum S (2017) Subclinical meningoventriculitis as a cause of obstructive hydrocephalus. BMJ Case Rep 11:2017
Beuy Joob

beuyjoob@hotmail.com

Sanitation 1 Medical Academic Center, Bangkok, Thailand

2 Hainan Medical University, Hainan, China 